\title{
INCIDENTAL DETECTION OF CARCINOMA IN SITU IN FIBROADENOMA OF BREAST IN A YOUNG WOMAN: A RARE FINDING
}

\author{
NIKITHA VALERINA KAIRANNA ${ }^{*}$, BRIJMOHAN KUMAR SINGH ${ }^{2}$, PAVITHRA P ${ }^{1}$ \\ ${ }^{1}$ Department of Pathology, Melaka Manipal Medical College, Manipal Academy of Higher Education, Manipal, Karnataka, India. \\ ${ }^{2}$ Department of Pathology, Kasturba Medical College, Manipal Academy of Higher Education, Manipal, Karnataka, India. \\ Email: nikita.kairanna@manipal.edu
}

Received 07 July 2018, Revised and Accepted: 17 August 2018

\section{ABSTRACT}

Fibroadenoma is the most common benign tumor of the breast in young females. Breast cancer arising within a fibroadenoma is a rare phenomenon. The incidence of carcinoma within a fibroadenoma is reported to be between $0.1 \%$ and $0.3 \%$ in a screened population, with a peak age of occurrence between the $4^{\text {th }}$ and $5^{\text {th }}$ decade. We present a case of 29 -year-old female with ductal carcinoma in situ in a background of fibroadenoma. There is a low percentage of fibroadenomas harboring carcinoma; however, all breast lumps should be seriously managed; extirpation and histological examination is recommended.

Keywords: Fibroadenoma, Carcinoma in situ, Benign tumor.

(C) 2019 The Authors. Published by Innovare Academic Sciences Pvt Ltd. This is an open access article under the CC BY license (http://creativecommons. org/licenses/by/4. 0/) DOI: http://dx.doi.org/10.22159/ajpcr.2019.v12i1.28326

\section{INTRODUCTION}

Fibroadenoma is the most common benign tumor of the breast in young females, which is treated with lumpectomy. It is more common in women during the $2^{\text {nd }}-3^{\text {rd }}$ decade of life [1].

Fibroadenoma is a benign tumor composed of stromal and epithelial components that display a wide variety of proliferative and nonproliferative histologic changes [1]. Although fibroadenoma is a benign tumor, there has been evidence of increased risk of association with invasive breast cancer [2,3].

It is difficult to assess the carcinoma component in fibroadenoma, because their features are similar to fibroadenoma [4]. They are found to contain both in situ and invasive malignancies. Furthermore, progression of the epithelial component to carcinoma in situ (CIS) and invasive carcinoma has been documented in the literature $[3,4]$. Cheatle and Cutler were the first to describe carcinoma arising in a fibroadenoma in 1939 [5].

The risk of developing carcinoma in fibroadenoma was common in complex fibroadenomas and during the $4^{\text {th }}-5^{\text {th }}$ decade of life [2]. However, the transformation of benign fibroadenoma to carcinoma is rare. Ductal CIS (DCIS) in a fibroadenoma not only changes the treatment modality but also the prognosis. We hereby report a rare case of DCIS arising from multiple fibroadenomas in a young female.

\section{CASE REPORT}

A 29-year-old female presented to the hospital with multiple lumps in both breasts for 8 years. There was no family history of breast carcinoma.

On clinical examination, there were multiple lumps in both the breasts, eight on the right side and four on the left side. The lumps had welldefined margins with smooth surface. They were firm in consistency and freely mobile. There was no tenderness, local rise in temperature, nipple discharge, or palpable axillary lymph nodes. Routine blood investigations were normal. A clinical diagnosis of multiple fibroadenomas was made.
Ultrasound of both the breasts revealed well-circumscribed, homogenous, and hypoechoic lesions. The features were suggestive of fibroadenoma of bilateral breasts (Fig. 1).

Fine-needle aspiration cytology was done and showed multiple cohesive clusters of branching papillary fronds of benign ductal epithelium suggestive of fibroadenoma (Fig. 2).

Based on the imaging and cytology reports, she underwent lumpectomy at Kasturba Hospital, Manipal, and the excised tissue was subjected for histopathological examination. Grossly, multiple, well-circumscribed, and encapsulated masses with the largest measuring $4 \mathrm{~cm} \times 2 \mathrm{~cm} \times 2.5 \mathrm{~cm}$ were noted (Fig. 3)

On cut section, they were homogenous, gray-white with slit-like spaces. On microscopy, benign compressed ducts with pericanalicular and intracanalicular proliferation were predominantly seen suggestive of fibroadenoma along with one lump showing nests of cells having pleomorphic nuclei, prominent nucleoli with atypical mitosis, and cribriform pattern suggestive of DCIS (Figs. 4 and 5).

The patient was healthy and there was no evidence of recurrent disease 12 months after the excision.

\section{DISCUSSION}

Fibroadenomas are the most common benign tumors of the breast. It mostly affects younger age females with peak incidence during the second to third decade of life. In our case, the age of the patient was 29 years who presented with multiple, mobile lumps in both the breasts and was diagnosed as fibroadenoma. These tumors are benign and carcinoma arising from fibroadenoma is a rare phenomenon. The frequency of carcinoma inside a fibroadenoma is $0.1-0.3 \%$, the median age for breast cancer was 61 years of age and was extremely rare in women $<30$ years of age [2-4].

Breast is a dynamic organ which undergoes physiological changes during puberty, menstruation, pregnancy, and lactation [6].

Triple test is done to evaluate breast lesions such as clinical examination, fine-needle aspiration cytology, and mammography [1,7]. There are 


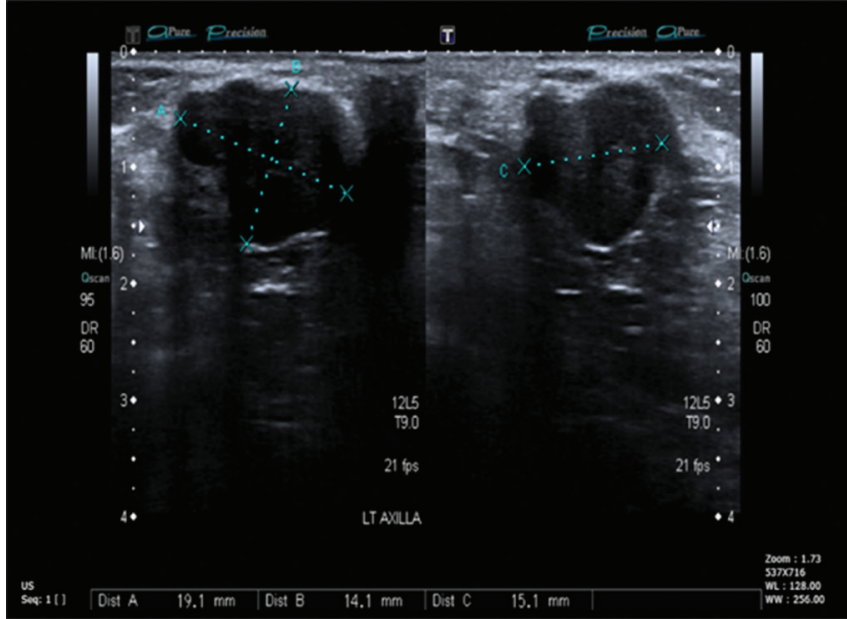

Fig. 1: Ultrasonography - hypoechoic lesion

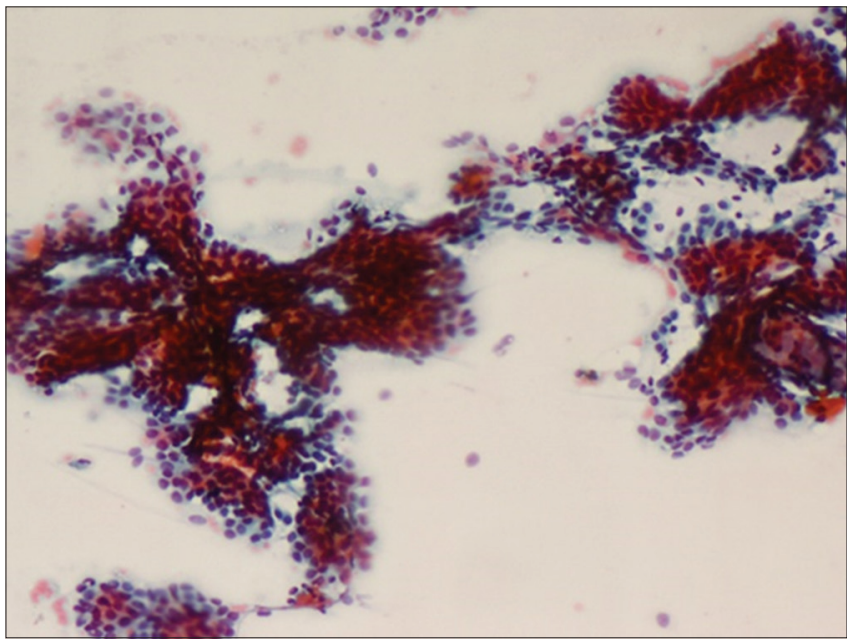

Fig. 2: Fine-needle aspiration cytology - cohesive clusters with branching papillary fronds

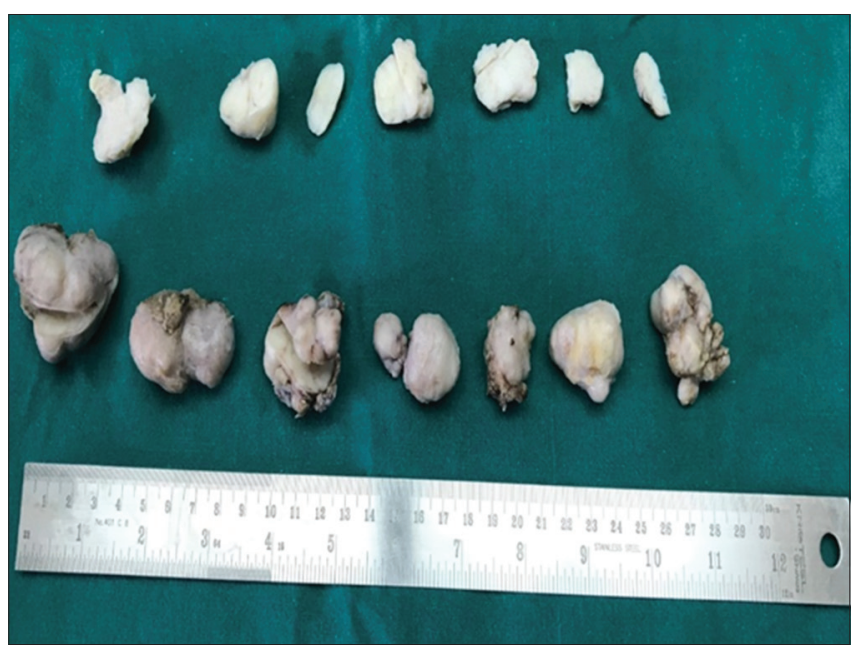

Fig. 3: Gross-multiple, well-circumscribed, encapsulated masses

no clinical criteria to suggest malignant focus has developed within a fibroadenoma [8]. The most common presenting symptom is a palpable mobile mass, occurring in $66 \%$ of patients, with a diameter varying from $0.5 \mathrm{~cm}$ to $10 \mathrm{~cm}[9,10]$. Fondo et al. reported microcalcifications

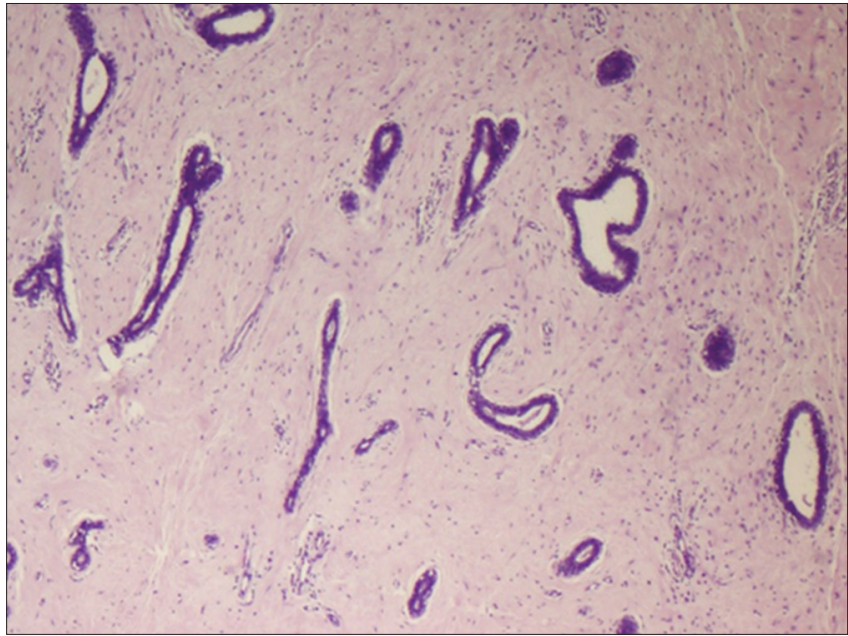

Fig. 4: $\mathrm{H}$ and $\mathrm{E}$ - fibroadenoma with compressed ducts

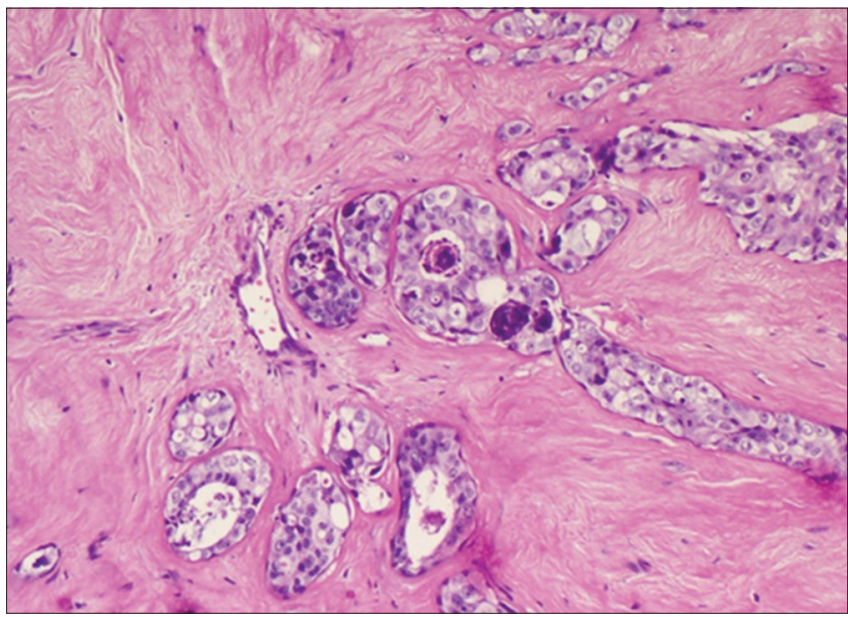

Fig. 5: $\mathrm{H}$ and $\mathrm{E}$ malignant cellular proliferation with comedo necrosis suggestive of ductal carcinoma in situ

inside the tumor in 4 of 9 cases. There were no such features in our study [11].

On sonography, fibroadenoma is an isoechoic or minimally hypoechoic, solid nodule that is generally associated with homogenous texture. Sonography findings are more useful than mammogram [7].

Fibroadenomas show various features such as proliferative epithelial changes such as hyperplasia, calcification, squamous metaplasia, adenosis, papilloma, CIS, and invasive carcinoma [1,12]. Fibroadenomas are classified as simple or complex. Complex fibroadenomas show many variations compared to simple fibroadenomas because of the presence of cysts ( $>3 \mathrm{~mm}$ ), sclerosing adenosis, epithelial calcifications, or papillary apocrine changes. This can lead to higher risk for transformation into malignancy [13]

Complex fibroadenomas and proliferative disease adjacent to fibroadenoma are associated with a slight increase in the risk of breast cancer. $66 \%$ of carcinomas inside fibroadenoma are lobular and $33 \%$ are ductal or mixed ductal and lobular; lobular CIS and DCIS have same frequency $[14,15]$. Pre-operative diagnosis of carcinoma arising from these lesions is difficult because of the close resemblance of presenting features with benign fibroadenoma [12-18].

Whether fibroadenoma is a risk factor for breast cancer remains uncertain, and several reports have discussed this phenomenon. Dupont et al. reported that the risk of invasive breast cancer was 2.17 times 
higher in patients with fibroadenoma and increased to 3.10 times higher in complex fibroadenomas. The risk of malignant change persisted even 20 years after the diagnosis of fibroadenoma. Other studies also provide strong evidence that fibroadenoma with hyperplasia is associated with an increased risk of breast cancer $[19,20]$.

Many criteria are followed to diagnose carcinoma in fibroadenoma. Diagnostic criteria of DCIS within fibroadenoma require showing at least one of the following findings.

- Intraductal carcinoma focus is also seen in the adjacent breast

- Intraductal proliferative lesions within fibroadenoma show cancer characteristic findings, for example, epithelial necrosis [20]

The older patient with a positive family history of breast carcinoma may have more clinical importance than younger women. The environmental risk factors are associated with breast carcinoma such as unhealthy dietary habits, obesity, use of unsafe cosmetics, estrogen exposure, hormone replacement therapy, use of oral contraceptives, and smoking [21]

Excision with breast conservative surgery done for in situ carcinoma arising in fibroadenoma. Radiotherapy and chemotherapy are usually not required but advised in advanced cases with axillary lymph node involvement. Early detection has good prognosis.

\section{CONCLUSION}

Carcinomas are common in complex fibroadenoma, in patients with family history of the breast carcinoma and the risk of carcinoma increases as age increases. Hence, all cases presenting in old age and positive family history are screened for any possibility of carcinoma. In the present study, it was a younger female, radiology and cytology revealed multiple fibroadenomas, but carcinoma was detected incidentally on histological examination. Hence, there is a need for extensive sampling to prevent false-negative diagnosis, especially in younger women.

\section{AUTHORS' CONTRIBUTION}

Dr. Nikitha, Dr. Brij, and Dr. Pavithra contributed to the design of the case report and to the writing of the manuscript and have reviewed the article.

\section{CONFLICTS OF INTEREST}

All authors have none to declare.

\section{REFERENCES}

1. Kujiper A, Mommers EC, Van der Wall E, Van Diest PJ. Histopathology of the fibroadenomas of the breast. Pathol 2001;115:736.

2. Abu-Rahmeh Z, Nseir W, Naroditzky I. Invasive ductal carcinoma within fibroadenoma and lung metastases. Int J Gen Med 2012;5:19-21.
3. Nayak R. Medullary breast carcinoma in a young female aged 30 : A rare case report. Int J Pharm Bio Sci 2014;5(3):461-4

4. Reddy KC, Kumar KM, Divyagna T. Incidentally detected carcinoma in situ in a fibroadenoma breast in a postmenopausal woman: A case report. Int Arch Integr Med 2015;2:197-202.

5. Cheatle GL, Cutler M. Tumours of the Breast. Their pathology, Symptoms, Diagnosis and Treatment. London: Edward Arnoled and Co.; 1931. p. 483.

6. Shah AK, Pathak R, Banerje Niazi M, Girishkumar HT. Lobular carcinoma-in-situ within a fibroadenoma of the breast. Postgrad Med J 1999;75:293-4.

7. Rao S, Latha PS, Ravi A, Thanka J. Ductal carcinoma in multiple fibroadenoma: Diagnostic inaccuracies. J Cancer Res Ther 2010;6:385-7.

8. Tiu CM, Chou YH, Chiou SY, Hsu CY, Chen SP, Chiang HR, et al. Development of a carcinoma in situ in a fibroadenoma. J Ultrasound Med 2006;25:1335-8.

9. Diaz NM, Palmer JO, Mc Divett RW. Carcinoma arising within fibroadenomas of the breast; A clinic pathologic study of 105 patients. Am J Clin Pathol 1991;95:614-22.

10. Ozzello L, Gump FE. The management of patients with carcinomas in fibroadenomatous tumours of the breast. Surg Gynecol Obstet 1985;160:9-104.

11. Fondo EY, Rosen PP, Frachia AA, Urban JA. The problem of carcinoma developing in a fibroadenoma. Cancer 1979;43:450-6.

12. Gashi-Luci LH, Limani RA, Kurshumliu FI. Invasive ductal carcinoma within fibroadenoma: A case report. Cases J 2009;2:174.

13. Limite G, Esposito E, Sollazzo V, Ciancia G, Formisano C, Di Micco R, et al. Lobular intraepithelial within breast fibroadenoma. BMC Res Notes 2013;6:267.

14. Kujiper A, Preisler-Adams SS, Rahusen FD, Gille JJ, Wall E, van Diest PJ. Multiple fibroadenomas harboring carcinoma in situ in a woman with a family history of breast/ovarian cancer. J Clin Pathol 2002;55:795-7.

15. Dupont WD, Page DL, Parl FF, Vnencak-Jones CL, Plummer WD Jr., Rados MS, et al. Long term risk of breast cancer in women with fibroadenoma. N Engl J Med 1994;331:10-5

16. Abe H, Hanasawa K, Naitoh H, Endo Y, Tani T, Kushima R. Invasive ductal carcinoma within a fibroadenoma of the breast. Int J Clin Oncol 2004;9:334-8

17. Stafyla V, Kotsifopoulos N, Grigoriades K, Kassaras G, Sakorafas GH. Lobular carcinoma in situ of the breast within a fibroadenoma. A case report. Gynecol Oncol 2004;94:572-4.

18. Kurosumi M, Itokazy R, Mamiya $\mathrm{Y}$, Kishi $\mathrm{K}$, Takayama $\mathrm{SH}$ Nagasawa $\mathrm{M}$, et al. Invasive ductal carcinoma with a predominant intraductal component arising in a fibroadenoma of the breast. Pathol Int 1994:44:874-7.

19. Azzopardi JG, Ahmed A, Mills RR. Problems in breast pathology. In: Bennigton JC, editor. Major Problems in Pathology. Edinburgh: WB Saunders Company Ltd.; 1979. p. 325-8.

20. Kwon MJ, Park HR, Seo J, Kim DH, Jung K, Lim YA, et al. Simultaneous occurrence of ductal carcinoma in situ within juvenile fibroadenoma in both breasts: A brief case report. Korean J Pathol 2014;48:164-6.

21. Preethi MI, Kumar PS, Karthikeyan S, Namboori PK. 'BRCA1' responsiveness towards breast cancer-a population-wise pharmacogenomic analysis. Int J Pharm Pharm Sci 2016;8:267-70. 